\title{
ESTUDOS DA INFÂNCIA - DIÁLOGOS CONTEMPORÂNEOS
}

Palomar é um instigante personagem de uma das obras do escritor italiano Ítalo Calvino, de mesmo nome. Metaforicamente se oferece como o perfeito anfitrião para convidar o leitor a adentrar este número de Teias. Inspirado no nome de um grande telescópio, Palomar é um senhor que é todo olhos e que vive a pensar sobre os modos como percebe o mundo ao seu redor: aceita o enigma que lhe imputam as folhinhas do gramado, o amor das tartarugas, o sutil instante que separa as ondas do mar, o assovio do melro, o espreitar de uma banhista de seios nus, enfim, aquilo que supostamente é trivial: a vida cotidiana. As descrições do senhor Palomar são tentativas de visualizar a profundidade e a complexidade presente nas coisas simples.

Destacamos aqui a experiência que narra no conto "A pantufa desparelhada" sobre o exato instante em que pretende usar, pela primeira vez, um par de pantufas, compradas num outro momento e numa longínqua cidade. Agora, já distante, ao calçá-las, percebe que as pantufas são desparelhadas, sendo um pé maior que o outro, resultado, talvez, de um comprar apressado aguçado pela desorganização do cesto de sapatos da loja onde fizera a compra. Olhando as pantufas, cada uma de um tamanho, Palomar ensaia perguntas que nos deslocam: E, se neste momento, num outro lugar, um outro homem, assim como eu, deseja, claudicante, desfazer essa confusão? Assim como penso nele, será que ele, entre o pé retorcido e um passo difícil, também pensará em mim? E se, na confusão daquele cesto, os sapatos desencontrados permanecerão anos a fio, recebendo em cima novas cargas de sapato, de modo que a percepção desse desencontro só venha a afetar alguém em outros tempos? Existiria outro comprador desatento a adentrar aquele bazar? Ou, quem sabe, seria justamente ele, Palomar, a pessoa que estaria corrigindo essa troca de tantos anos, quem sabe séculos. Que alteridades habitavam aquelas pantufas desparelhadas? Dando a ver a complexidade que reside na simplicidade da vida cotidiana, Palomar extrai das pantufas uma ética, decidindo por usá-las, assim mesmo, desparelhadas, em solidariedade com esse alguém que, em outros tempos ou lugares é, para ele, um par.

$\mathrm{Na}$ esteira das provocações de Palomar que sugere que o tamanho do mundo é proporcional à sede do olhar, podemos pensar que os desafios contemporâneos que se colocam para o campo dos Estudos da Infância se equilibram num constante jogo que consiste em saber se a infância têm a dimensão das nossas indagações ou se as pesquisas que fazemos têm a proporção dos enigmas que a infância nos dirige, se a construção de um olhar para a infância que a reconheça em sua 
especificidade forma par ou desparelha com o reconhecimento de que o modo infantil de olhar é a centelha necessária para a pesquisa. Que perguntas a infância provocaria em Palomar? Que desparelhamentos traria à tona? Que éticas extrairia ao transformar a Infância em questão?

A ideia deste número temático fora gestada no I Congresso de Estudos da Infância, evento organizado pelo Departamento de Estudos da Infância da Faculdade de Educação da UERJ, que teve sua primeira edição no ano de 2017. Realizado num contexto de profunda crise e abandono de nossa Universidade por parte do Governo do Estado do Rio de Janeiro, tanto em termos do custeio necessário para manutenção do trabalho cotidiano quanto em termos de atrasos em vários meses dos salários de seus trabalhadores, a resposta que tivemos foi uma participação de amplo espectro nacional e internacional. À nossa desparelhada conjuntura somaram-se pesquisadores, estudantes, interessados pela temática da infância, pares na compreensão de que a UERJ, em certa medida, é(ra) o par (des)encontrado de todas as Universidades Brasileiras em tempos golpistas e temerosos. Em meio a trocas de saberes e práticas de investigação, encontros, debates sobre a infância e as crianças, mais de 400 pessoas inscritas, com mais de 200 trabalhos apresentados, nos ajudavam a permanecer firmes na luta e a fortalecer o apoio coral que afirmava que A UERJ RESISTE. Tanto resiste que, mesmo numa conjuntura que ainda exige de nós muita luta, colocamos agora online um grupo de textos - que compõem um conjunto de temáticas diversas - resultantes do convite feito naquele Congresso para que os participantes submetessem seus textos à Teias, Revista de nossa Faculdade de Educação. Somam-se a eles textos de recepção em fluxo contínuo que também entendemos reafirmarem o lugar de importância de nossa Universidade no cenário político nacional.

Tendo Palomar como anfitrião, convidamos o leitor aos textos e às indagações que neles residem, provocativas de novas indagações para o campo dos Estudos da Infância. Tal como as pantufas de Palomar, sua diversidade é abertura para a alteridade constituinte do campo dos estudos da infância. Apontam desconfortos sobre o lugar social da infância na sociedade e na cultura, ao mesmo tempo em que pontuam que uma história social e cultural que não considere a perspectiva das crianças é incompleta e parcial. Assim, abrindo a seção EM PAUTA, o artigo de Márcia Gobi, "Entre a casa, a rua e a escola: o que o menino viu? Itinerários de uma criança em São Paulo", é inspirador e primoroso por tratar dos olhares de Zé Carlos sobre a sua cidade, no seu percurso casaescola-casa. É pelos olhos de uma criança que conhecemos os problemas e as belezas da cidade de São Paulo. Zé Carlos registrou por meio de fotografias as coisas importantes do seu mundo e Márcia fez uma bela análise dos olhares da(s) criança(s) e dos nossos olhares para elas e a cidade. No jogo de olhares semelhante ao de Palomar, o texto de Márcia convida a lembrar que não há como olhar a criança, sem ser olhado por ela também. 
Na sequência, o texto "Crianças Tupinambá: rios, colinas, bancos de areia e matas como lugares do brincar cotidiano", de Léa Tiriba e Christiana Cabicieri Profice, traz para o debate os processos de escolarização de crianças indígenas Tupinambá de Olivença, no estado da Bahia, destacando as suas relações com a natureza, fundamentais para o sentimento de pertencimento das crianças. O texto é parte de uma pesquisa que busca integrar-se aos saberes locais e contribuir para a implementação de políticas que qualifiquem o cotidiano de crianças e seus professores em consonância com os modos de vida de suas comunidades

No texto "Quem disse que as questões raciais não afetam os bebês?" Circe Mara Marques e Leni Vieira Dornelles nos apresentam a problemática das questões raciais presentes em uma creche. É um importante e necessário estudo teórico-empírico realizado a partir da parceria entre universidade, alunas da graduação do curso de pedagogia e escola de educação infantil. É um estudo que contou com a participação de crianças, professoras e gestores. Além disso, as autoras colocam em debate a potência dos bebês e as práticas que provem a igualdade racial. Problemáticas essenciais em nossa época.

$\mathrm{O}$ artigo de Fabiana Oliveira, "O lugar e o tempo das culturas infantis nas pesquisas brasileiras" é de grande importância para os estudos da infância, pois abrange um levantamento bibliográfico no IBICT (Instituto Brasileiro de Informação em Ciência e Tecnologia) de pesquisas sobre as culturas infantis. É curioso e interessante constar, através do artigo, que grande parte dos estudos das culturas infantis ainda ocorrem nas escolas de educação infantil, um espaço institucionalizado e produzido para a infância. Será esse o território das crianças? Que força territorial imperativa é essa que é instituída para as crianças?

Dois textos na sequência ajudam-nos a problematizar a temática da infância a partir de um olhar histórico que reafirma a importância de problematizar o passado com as indagações que o presente provoca. Como eram os ritos de velório e os sepultamentos de crianças entre 1910-1914, em Belém do Pará? Tratar da morte de crianças, um tema pouco comum nos estudos da infância, é a questão abordada pelas pesquisadoras Carmeci dos Reis Viana e Laura Maria Silva Araújo Alves. Para responder essa pergunta, a fonte de pesquisa das autoras são os periódicos impressos jornalísticos que retratam as práticas, crenças e superstições desta época. "Infância e experiências educativas no educandário Eunice Weaver em Belém/Pará (1942-1980)", de Tatiana do Socorro Corrêa Pacheco, por sua vez, traz um olhar para a infância a partir da memória de ex-internos desse educandário, um ponto de vista singular sobre o educandário, a época, as políticas higienistas de então. 
Nessa linha das reflexões sobre a institucionalização da infância, Pinóquio, leitura e escolarização das crianças pequenas: como transformam-se em bonecos", de Talula Montiel Trindade e Sandra Regina Simonis Richter traz pertinentes indagações para se pensar o lugar da leitura na escola e na vida das crianças, a partir de cartas trocadas entre crianças maiores para crianças menores em torno ao tema da escola.

O texto "Teatro e performance na educação infantil: [cor]possibilidades para uma educação sensível”, de Jean Carlos Gonçalves, Rafael Koehler e Michelle Bocchi Gonçalves traz como proposta central pensar a infância na contemporaneidade destacando a necessária atenção ao corpo infantil num contexto de virtualidades. Os autores apontam para a urgência de uma educação que se comprometa com a sensibilidade humana e com uma educação sensível desde a Educação Infantil.

Fechando os artigos de EM PAUTA, "Kairós: valsar com a infância, na escola, através da experiência filosófica" de autoria de Gustavo Tanus Martins, propõe a partir de uma abordagem crítica e filosófica, uma reflexão e uma desconstrução da ideia normatizada e engessada tanto da infância quanto da escola. Gustavo nos apresenta vários questionamentos que contribuem não apenas para adensar os argumentos propostos no seu texto, que apontam para a possibilidade de narrar a infância com outras lentes, como para repensarmos o nosso lugar de pesquisadores e pesquisadoras do campo dos Estudos da Infância, de modo a desparelhar as nossas certezas e se abrir para a singularidade apresentada pelas crianças.

$\mathrm{Na}$ seção ELOS, trazemos dois textos de autores estrangeiros. No artigo "La sobreinfantilización de la infancia: un problema para todos”, Claudia Yarza dá visibilidade ao protagonismo das crianças integrantes de movimentos sociais na América Latina e a sua capacidade auto-organizativa. A partir dele, a autora interpela o olhar adulto que sobre-infantiliza às crianças mostrando vínculos que o ligam a um olhar colonialista que, por sua vez, infantiliza ao índio, à mulher, ao cidadão.

Malvina Argumedo, com o texto "Corporalidades, temporalidades e infancias: la pregunta por la hospitalidad desde la escuela", problematiza o espaço das escolas hospitalares, onde o discurso pedagógico hegemónico se cruza com o discurso médico em um afã normalizador da infância. Além disso, ela se propõe pensar na possibilidade de encontros hospitaleiros que acolham e reconheçam os corpos, as temporalidades e as existências das crianças hospitalizadas.

Para este número, a Revista Teias traz uma entrevista com Paula Mendonça de Menezes, sistematizada sob o título "Um olhar sobre a infância indígena" por Beatriz Fabiana Olarieta, Conceição Firmina Seixas Silva e Lisandra Ogg Gomes. A conversa se constrói na abrangência de 
um olhar que carrega uma ampla experiência na tensa e complexa tarefa de levar a escola a comunidades indígenas e que se abre à aventura de explorar, a partir do cinema, o brincar, a cultura e a participação das crianças do povo Yudja, que habita as margens do Rio Xingu, no Estado de Mato Grosso.

Para finalizar este número, recebemos 2 presentes: um, foi a recomendação da leitura do livro "A casa e o mundo lá fora: cartas de Paulo Freire para Nathercinha”, de Nathércia Lacerda, Cristina Laclette Porto e Denise Sampaio Gusmão. E o outro, é a resenha poética e instigante de Mariangela Momo, que faz uma bonita interpretação entre as experiências e memórias das personagens do livro e a sua própria experiência e memória. Dialogando com as cartas trocadas entre Paulo Freire e sua sobrinha Nathércia, o livro convida a pensar as muitas experiências e temporalidades históricas que demarcam o encontro entre crianças e adultos - sejam eles pesquisadores, professores, sujeitos da vida comum. "A casa e o mundo lá fora" parecem nos levar de novo ao encontro de Palomar: que complexas indagações cabem na simplicidade do cotidiano? Que mundos se abrem com o olhar indagativo das crianças?

Beatriz Fabiana Olarieta

Conceição Firmina Seixas

Lisandra Ogg Gomes

Rita Ribes Pereira 